\title{
IDENTIFIKASI KEBERADAAN BENDA ASING PADA AREA PENGUKURAN TOMOGRAFI DENGAN MENGGUNAKAN METODA ELECTRICAL IMPEDANCE TOMOGRAPHY (EIT) BERBASIS LABVIEW
}

\author{
Endang Wijaya ${ }^{1}$ dan Sastra Kusuma Wijaya ${ }^{2}$ \\ 1)Jurusan Teknik Elektro,Politeknik Negeri Jakarta \\ Jl. Prof. G. A. Siwabessy, Kampus UI Depok 16425 \\ 2)Jurusan Fisika Fakultas Matematika dan Ilmu Pengetahuan Alam \\ Universitas Indonesia \\ Email :2)saywijaya@gmail.com
}

\begin{abstract}
EIT (Electrical Impedance Tomography) is one of several tomographic methods to estimate impedance distribution in a domain based on the measurement of a boundary area in a certain area. This method is widely used to observe the presence and growth of foreign matter in the area observed, such as cancer in the breast.

In this study an instrument was designed to identify the presence and geometry of foreign objects, which were placed in the area of tomography measurement (phantom) in the form of three-dimensional (3D) images, Data acquisition instrument uses NI USB 6351 and LabVIEW (hard \& software), with I testing and analysis of $3 D$ image reconstruction using a modeling algorithm "n3r2",

The test results can be concluded that the EIT instrument model is able to detect the presence and location of test samples placed in the tomography measurement area (phantom), although 3D images that appear to be unrepresentative illustrate the geometry of the test sample. This is due to an error in the data generated by three (3), namely S0-S1, S1-S2, and S31-S.
\end{abstract}

Keysword : Method, EIT, LabView, 3D, algoritm"n3r2"

\section{ABSTRAK}

EIT (Electrical Impedance Tomography) adalah satu diantara beberapa metode tomografi untuk memperkirakan distribusi impedansi dalam suatu domain berdasarkan pengukuran daerah batas di tertentu. Metode ini banyak digunakan untuk mengamati keberadaan dan pertumbuhan benda asing pada daerah yang diamati, seperti kanker pada payudara.

Dalam penelitian ini dirancang instrumen untuk mengidentifikasi keberadaan dan bentuk geometri benda asing, yang diletakkan pada daerah pengukuran tomografi (phantom) dalam bentuk gambar tiga dimensi (3D), Instrument akuisisi data menggunakan NI USB 6351 dan LabVIEW (hard \& software),dengan I pengujian dan analisis rekonstruksi gambar 3D menggunakan dengan pemodelan algoritma "n3r2",

Hasil pengujian dapat disimpulkan bahwa model instrumen EIT mampu mendeteksi keberadaan dan lokasi sampel uji yang diletakkan`di dalam area pengukuran tomografi (phantom), meskipun gambar 3D yang nampak belum representatif menggambarkan bentuk geometri dari sampel uji. Hal ini disebabkan adanya kesalahan data yang dihasilkan oleh tiga (3) yaitu S0-S1, S1-S2, dan S31-S0.

Kata kunci: Metode, EIT, LabView, 3D, algoritma"n3r2"

\section{PENDAHULUAN}

Penelitian di bidang tomografi saat ini terus berkembang, sejalan dengan berkembangnya kebutuhan instrumen untuk mendeteksi keberadaan atau perkembangan suatu obyek pada area pengamatan. Metoda ini banyak digunakan pada bidang medis, diantaranya untuk mengamati

$$
\begin{aligned}
& \text { pertumbuhan kanker payudara, } \\
& \text { pengamatan volume darah, dan } \\
& \text { sebagainya. Sedangkan aplikasi di } \\
& \text { industri, diantaranya adalah untuk } \\
& \text { mengetahui keretakan yang terjadi pada } \\
& \text { spesimen penghantar listrik, sebaran } \\
& \text { impedansi pada bahan ferromagnetik, } \\
& \text { dan lain-lain. }
\end{aligned}
$$

Diantara beberapa metoda tomografi yang digunakan, satu diantaranya adalah 
EIT (electrical impedance tomography). Beberapa alasan digunakannya metode ini antara lain non-invasif, non-radiasi, non-ionisasi, dan murah. Akan tetapi, karena sinyal yang dihasilkan mudah terganggu oleh noise, maka diperlukan teknik pengukuran yang mampu memilah secara presisi antara sinyal yang diukur dengan noise.

Selain perkembangan pada teknik pengukurannya, berbagai software khusus juga dikembangkan untuk mengolah data numerik (tegangan dan arus) hasil pengukuran menjadi imformasi gambar 3D, yang mempresentasikan bentuk obyek yang diamati. Selain akurasi hasil pengukuran, kecepatan pengukuran sampai menghasilkan gambar 3D (satuan frame per-detik) menjadi tolok ukur performa sistem EIT.

Kemampuan dan fasilitas yang dimiliki oleh Software LabVIEW (Laboratory Virtual Instrumentation Engineering Workbench) dan hardware NI USB6351 untuk otomasi akuisisi dan strukturisasi data, dan software EIDORS (Electrical Impedance Tomography and Diffuse Optical Tomography Reconstruction Software) untuk rekonstruksi gambar 3D memungkinkan untuk diimplementasikan dalam pembuatan instrumen EIT.

\section{METODE PENELITIAN}

Metoda penelitian yang dilakukan adalah melakukan kajian literatur cetak dan elektronik tentang instrumen EIT; menyiapkan peralatan instrumen pendukung penelitian yang diperlukan di Laboratorium Teknik Instrumentasi dan Kontrol, Jurusan Teknik Elektro, Politeknik Negeri Jakarta; membuat model elektroda anti korosif dan model ruang pengamatan; membuat model rangkaian antarmuka analog mux/demux 2 x 16 yang mampu bekerja pada frekwensi $10 \mathrm{kHz}$, dengan kecepatan pensaklaran $\leq 1$ mili-detik standar CMOS (complementary metal oxide semiconductor); membuat model rangkaian sumber arus sinusoida konstan 0,1 mA dengan frekwensi $10 \mathrm{kHz}$; membuat model perangkat lunak untuk pengendalian proses akuisisi dan strukturisasi data pengukuran distribusi tegangan menggunakan LabVIEW Versi 2009; merekontruksi data pengukuran distribusi tegangan menjadi gambar 3D, sebagai representasi dari bentuk sampel obyek yang diamati dengan menggunakan software EIDORS; melakukan pengujian dan analisis data rancangan model instrumen EIT serta menyimpulkan hasilnya.

\section{HASIL DAN PEMBAHASAN}

Luaran dari hasil penelitian ini adalah sebuah model instrumen EIT berbasis instrumentasi maya menggunakan software LabVIEW 2012 dan EIDORS. Sedangkan tolok ukur keberhasilannya adalah terealisasinya model instrumen EIT yang memiliki kemampuan untuk:

- mengidentifikasi keberadaan dan lokasi dari obyek sampel di dalam ruang pengamatan tomografi.

- menggambarkan bentuk 3D dari objek sampel di dalam ruang pengamatan tomografi pada layar komputer.

Konfigurasi instrumen EIT hasil rancangan diperlihatkan pada Gambar 1, terdiri dari 2x16 Elektroda, Ruang Pengamatan Sampel, Rangkaian Mux/Demux, Rangkaian Konverter V/I, Modul Akuisisi Data, Komputer, Program Akuisisi data, dan Program Rekonstruksi Gambar. Akuisisi data menggunakan metoda Neighboring untuk mengkoleksi data impedansi dari 2x16 elektroda yang ditempatkan pada 
tabung silinder menggunakan bahan acrylic.

Daerah pengamatan tomografi (phantom) dirancang berbentuk tabung silinder menggunakan bahan acrylic, diameter $200 \mathrm{~mm}$, tinggi $200 \mathrm{~mm}$, dan tebal $5 \mathrm{~mm}$. Jumlah elektroda dibuat sebanyak 32 buah, menggunakan bahan tembaga yang dilapisi perak, dengan ukuran panjang $15 \mathrm{~mm}$, lebar $10 \mathrm{~mm}$, dan tebal 0,2 mm. Pemasangan elektroda di bagi menjadi 2 slice, yaitu slice 0 dan 1 . Masing-masing slice terdiri dari 16 elektroda yang dipasang mengelilingi permukaan bagian dalam tabung, sehingga membentuk 2 row dan 16 column. Jarak antar row adalah 50 mm, sedangkan jarak antar column 39,25 mm. Hasil rancangan diperlihatkan pada Gambar 2. Sedangkan hasil rancangan keseluruhan model EIT diperlihatkan pada Gambar 3.

Hasil pengujian sampel pada lima lokasi yang berbeda diperlihatkan pada Gambar 4. Berdasarkan hasil pengujian tersebut, gambar 3D yang paling representatif menggambarkan kondisi sebenarnya adalah saat sampel diletakkan di depan dekat dengan elektroda S0. Daerah yang didominasi warna biru adalah daerah dengan distribusi impedansi besar, yang merupakan representasi dari impedansi sampel yang terbuat dari bahan isolator PVC. Sedangkan pada empat lokasi sampel yang lain belum merepresentasikan kondisi yang sebenarnya. Dapat dipastikan bahwa kesalahan terjadi pada data hasil akuisisi dengan kecurigaan terbesar terjadi kesalahan pada rangkaian multiplekser. Untuk membuktikan kecurigaan tersebut perlu dilakukan penelitian lebih lanjut.

\section{KESIMPULAN}

Hasil pengujian dan analisis rekonstruksi gambar 3D menggunakan program EIDORS untuk pemodelan algoritma "n3r2” dapat disimpulkan bahwa:

a. Model instrumen EIT hasil penelitian dapat mendeteksi keberadaan sampel uji yang diletakkan`di dalam area pengukuran tomografi (phantom), akan tetapi belum bisa mendeteksi secara akurat lokasinya.

b. Hasil gambar 3D yang dihasilkan belum representatif menggambarkan bentuk geometri sampel uji yang diletakkan`di dalam area pengukuran tomografi (phantom). Hal ini terlihat dari distribusi impedansi yang tidak homogen pada daerah lokasi sampel uji. Dapat dipastikan kesalahan terjadi pada data hasil akuisisi dengan kecurigaan terbesar penyebabnya pada rangkaian multiplekser.

\section{UCAPAN TERIMAKASIH}

Pada kesempatan ini penulis mengucapkan terima kasih kepada,

- DR. Sastra Kusuma Wijaya, sebagai dosen pembimbing yang dengan penuh kesabaran membantu dan mengarahkan peneliti dalam menyelesaikan tesis ini.

- DR. Prawito, DR. Supriyan, dan DR. Drs. A. Tossin Alamsyah, S.T., M.T sebagai dosen penguji yang telah banyak memberikan pencerahan di bidang teknik tomografi.

- Prof. DR. Ir. Johny Wahyuadi M Sudarsono, DEA, sebagai Direktur Politeknik Negeri Jakarta (PNJ) yang telah mendukung dan mengijinkan penulis untuk melanjutkan sekolah magister di FMIPA UI melalui fasilitas BPPS. 


\section{DAFTAR PUSTAKA}

[1] L. A. M. Mello, et al., 2008. “ThreeDimensional Electrical Impedance Tomography: A Topology Optimization Approach", IEEE Transactions on Biomedical Engineering, Vol. 55 No. 2, February

[2] Helga Ross, 2010. "Technical Developments to Enable Electrical Impedance Tomography (EIT) Measurement of Blood Flow to Monitor Cardiac Output”, Thesis,
Carleton University Ottawa, Ontario, Canada.

[3] Antti Nissinen, 2011.”Modelling Errors in Electrical Impedance Tomography" , Dissertations in Forestry and Natural Sciences, Publication of The University of Eastern No. 32, Finland.

\section{LAMPIRAN}

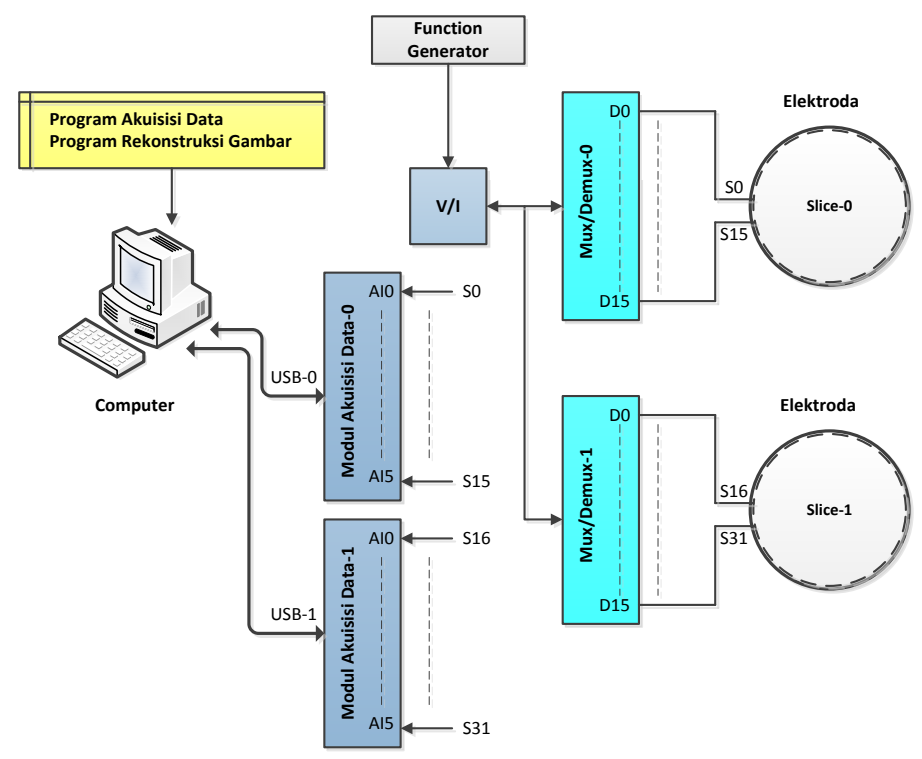

Gambar 1 Rancangan konfigurasi model instrumen EIT

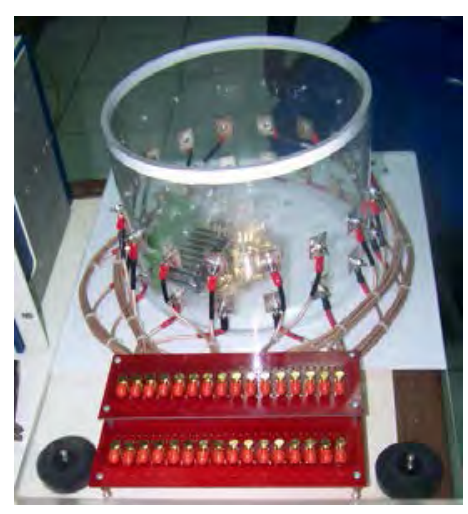

Gambar 2 Hasil rancangan elektroda dan daerah pengamatan 

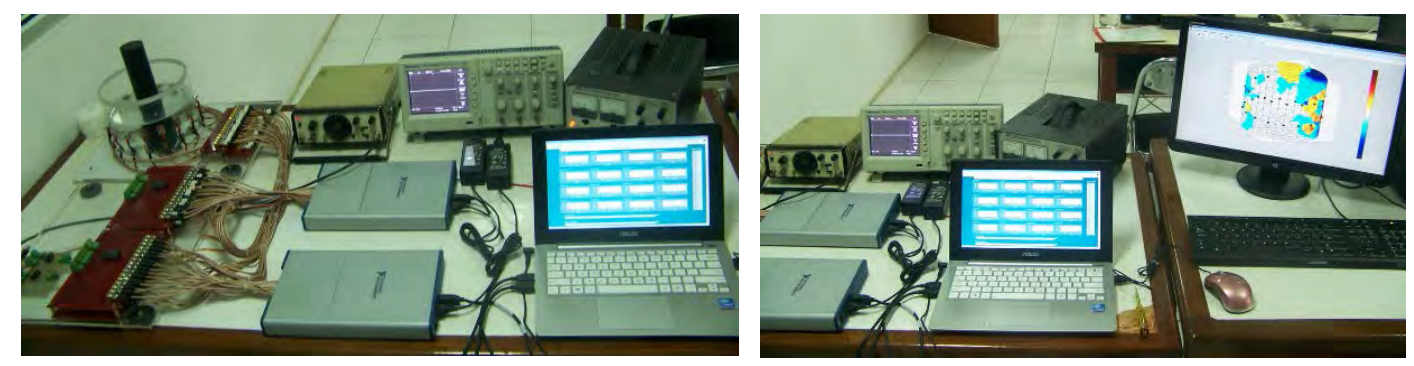

Gambar 3 Realisasi model instrumen EIT
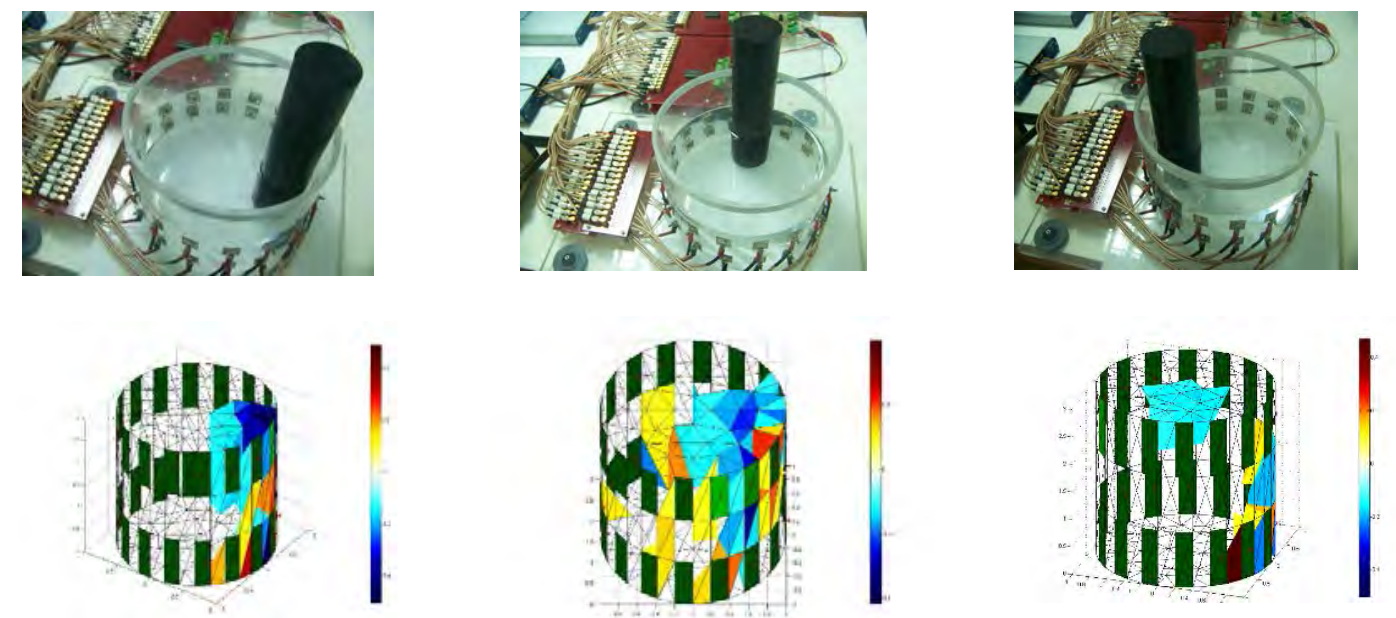

(a) Letak sampel S0

(b) Letak sampel S4

(c) Letak sampel S8
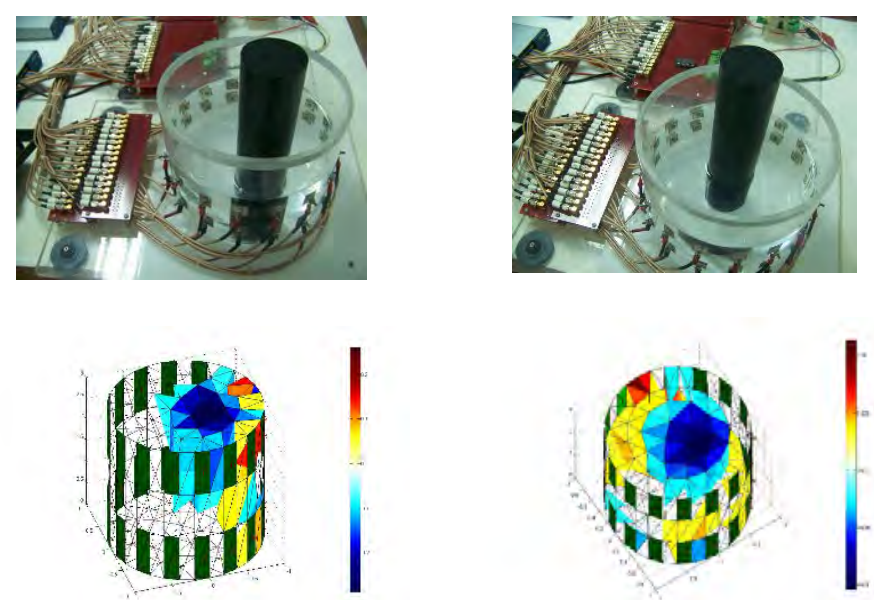

(d) Letak sampel S12

(e) Letak sampel SCT

Gambar 4 Letak sampel uji dan hasil identifikasi gambar 3D 
Endang Wijaya dan Sastra Kusuma Wijaya, Identifikasi Keberadaan Benda... 